\title{
Revitalising PBL Groups: Evaluating PBL with Study Teams
}

\author{
JOS MOUST ${ }^{1}$, HERMA ROEBERTSEN ${ }^{1}$, HANS SAVELBERG ${ }^{2} \&$ \\ ANGELIQUE DE RIJK ${ }^{3}$
}

${ }^{1}$ Department of Educational Development and Research, ${ }^{2}$ Department of Human Movement Sciences, and ${ }^{3}$ Department of Health Organisation, Policy and Economics, Faculty of Health Sciences, University of Maastricht, Maastricht, The Netherlands

\begin{abstract}
Context: In problem-based learning (PBL), students are actively engaged with psychological learning principles as activation of prior knowledge, elaboration and organization of knowledge. In their tutorial groups, however, students do not always apply these principles when working with a procedure like the "Seven-Jump" method. To stimulate students to use these principles more often, they were offered another format within a PBL context: PBL with study teams. During the period of self-study, students work on a regular basis in so-called study teams, small groups of 3-4 persons. In these groups they explain to each other their learning outcomes, clarify for each other their problems while studying texts and organize their knowledge to present this to the members of other study teams in their tutorial group. Previous research showed that students spent more time on self-study in a PBL with study team condition than in a traditional PBL context. In this study the achievement as well as appreciation of students participating in a PBL with study teams' environment, is compared with students working in a traditional PBL environment.

Objectives: To determine whether PBL with study teams differs from the traditional PBL environment in students' appreciation and study time.

Methods: We conducted an experiment in two blocks over two years. Questionnaires were administered to collect data on appreciation and time for self-study.

Results: Students' appreciation of the two formats did not differ much. The large standard deviations indicate considerable differences in appreciation between individual students. Appreciation was slightly higher in the second experiment when instructions about how to collaborate were less strict. Students devoted twice as many hours studying in the study group format compared with the traditional PBL format.
\end{abstract}

Author for correspondence: Jos Moust, Department of Educational Development and Research, Faculty of Health Sciences, Maastricht University, PO Box 616, 6200 MD Maastricht, The Netherlands. Tel: + 31 433885747. Fax: +31433885779. E-mail: j.moust@educ.unimaas.nl 
Conclusions: The students indicated that they enjoyed the format but that the increased workload disturbed their customary study rhythm. Assessment scores and tutors' impressions suggest that study teams foster deeper learning for understanding. Whether this can be attributed to more intensive individual and collaborative elaboration activities should be the subject of further studies.

KEYWORDS Problem-based learning, study teams, self-directed learning, tutorial groups.

\section{Introduction}

Problem-based learning (PBL) can create a powerful learning environment. PBL supports students' self-directed learning, engages students in a professional learning context and fosters important principles of learning. All these processes are regulated by the tutorial groups. In these groups, students tackle a problem, text describing phenomena or events that need to be understood and resolved, in a predefined stepwise sequence of activities "The Seven-Jump" method (Schmidt, 1993). During the first steps, students activate relevant prior knowledge by identifying what they already know, elaborate, organize their common knowledge and discuss what new knowledge they need to acquire. They derive learning objectives which are then pursued through self-directed study. The results of the self-study are reported in a successive group session, the phase of synthesis. By discussing, appraising and schematizing what they have discovered, students elaborate, restructure, integrate their collective knowledge and apply it to solve the problem (Schmidt \& Moust, 2000). Generally, students experience a PBL environment as nurturing.

For many years, PBL has been used successfully in the Faculty of Health Sciences of Maastricht University, the Netherlands. Recently, however, there have been signals that students' enthusiasm for the PBL process may be on the wane, and the intended cognitive processes are not always applied properly in tutorial groups (Moust et al., in press; Dolmans et al., 2001).

Results of the regular programme evaluation indicate that after 18 months students become bored with the repetitious routine of working through problems using "The Seven Jump" method. Students indicate that the problems and the approach used in the tutorial group cease to be challenging and motivating. The PBL process tends to become ritualized, with students skipping the stage of elaboration of prior knowledge. The discussion in the second meeting is reduced to presentation of the main results, with no attempts being made to appraise opinions and viewpoints or synthesize the findings. Students shirk their responsibility to take an active part in the discussions out of lack of interest, laziness, uncertainty or incompetence (Dolmans et al., 2001). An evaluation of the number of hours students spent on self-study showed a 
considerable decrease over the course of a few years (Van Berkel \& Van den Hurk, 2001).

There are several explanations for the deterioration of the PBL process.

Some problem designers and tutors still believe students are incapable of fruitful self-directed study. By prescribing lists of learning resources and key words, they steer students' learning too much into the desired direction. This often results in poor discussions and less elaboration in the tutorial groups (Moust et al., in press).

Despite a teacher training programme and guidelines for problem design, some curriculum developers offer too many over-structured and fewer complex problems in the first year of the curriculum. This type of problem induces rather poor or superficial problem analysis with few elaborations (De Grave, 1998) and may encourage students to focus quickly on one solution or "right answer" (Houlden et al., 2001).

Increase in tutorial group size due to lack of government funding. The Maastricht Faculty of Health Sciences has had to increase tutorial group size from eight to 12 students. Research by Lohman and Finkelstein (2000) showed that students' self-directedness increased in small (three students) and medium (six students) sized groups but decreased in large groups (nine or more students).

To optimize students' educational opportunities, Maastricht Faculty of Health Sciences has explored several cooperative small-group learning formats in a PBL-environment. These might prevent or stop the deterioration of the learning processes described above. PBL with study teams is such a format (see Table 1).

\section{PBL with study teams}

In traditional PBL tutorial groups students prepare themselves mostly in an individual way for the next tutorial meeting. As in the conventional PBL track, in a PBL with study teams' format, the whole tutorial group works together during the phase of analysis, during which they analyse problems that can be solved from different points of views. After analysing, the tutorial group is split up into four study teams of three students each. Members of these study teams decide which learning resources they will use to pursue the learning objectives. It is important to notice that the learning objectives are not distributed among the study teams or within one study team. Students have to start their discussion on more or less the same basis. The members of a study team can meet several times to discuss the results of their self-study, explain to each other subject matter they do not understand and formulate points of discussion for the next tutorial group meeting. In addition to their explanations and solutions of a problem, each study team has to prepare a presentation for the next tutorial group meeting. This presentation gives the members of the other 
Table 1. Similarities and differences between traditional PBL and PBL with study teams

\section{Similarities}

One tutorial group member is the chairperson during the analysis phase and the synthesis phase

Principal method of discussion: identification of unfamiliar terminology, elaboration of prior knowledge, identification of gaps in knowledge, identification of learning objectives, self-study, reporting on self-study, discussion and synthesis.

Tutorial group is guided by a tutor

All the learning objectives are studied by all tutorial group members

\section{Differences}

Traditional $P B L$

Two group sessions (2 hours) per week

The problems offered to the students consist of few concepts and connections between the concepts. The problems are concise and well-structured.
PBL with study teams

One group session (2.5 hours) per week The problems offered to the students consist of many concepts and connections between the concepts. The problems are complex, ill-structured and require more than one solution or explanation.

Students are free to collaborate with other Students are obliged to meet other stustudents during their period of self-study dents in a study team during their period of self-study

Students are free in how they prepare for The members of a study team have to the synthesis phase

Preparation for the synthesis phase is highly student dependent

The synthesis phase is not structured

Individual assessment by a set of open questions at the end of the block prepare an overview for presentation in the synthesis phase of the next tutorial meeting Preparation for the synthesis phase is structured by the discussions in the study teams and the presentations students have to prepare

The synthesis phase is structured by the presentations of the various study teams and the discussion between the members of the study teams

Individual assessment by a set of open questions at the end of the block and group assessment of the presentations in the tutorial meetings

Attention for the process of collaboration Attention for the process of collaboration in the tutorial group is tutor and student in the study team and the tutorial group is dependent explicated in the unit portfolio.

study teams an overview of the content of their discussion within the team. The presentation can be a concept map or a series of transparencies. Additionally each study team has to formulate critical questions about the literature studied. In the next plenary tutorial group the presentations of the study teams are offered to the members of the other study teams and discussed. In a general round up, the critical questions of every team are answered, and the solutions 
of every team integrated to solve the problem from various perspectives. Figure 1 offers a schematic overview of a PBL learning environment with study teams.

\section{Research questions}

In order to explore the feasibility of PBL with study teams, the Faculty of Health Sciences used this approach in two blocks in two consecutive academic years. The purpose of the experiment was to answer the following research questions:

1. Do students appreciate the learning environment of PBL with study teams?

2. Does the amount of time students spend studying differ between the study team approach and the traditional PBL approach?

3. Does a PBL environment with study teams improve students' achievement compared with the traditional PBL environment?

\section{Methods}

Two experiments were carried out in two different blocks of six weeks in the second year of the health sciences curriculum. One block (block A) was part of the Work and Rehabilitation stream and focused on the prevention and rehabilitation of damaging processes in labour situations, such as low back pain, repetitive strain injury and the sick building syndrome. The other block

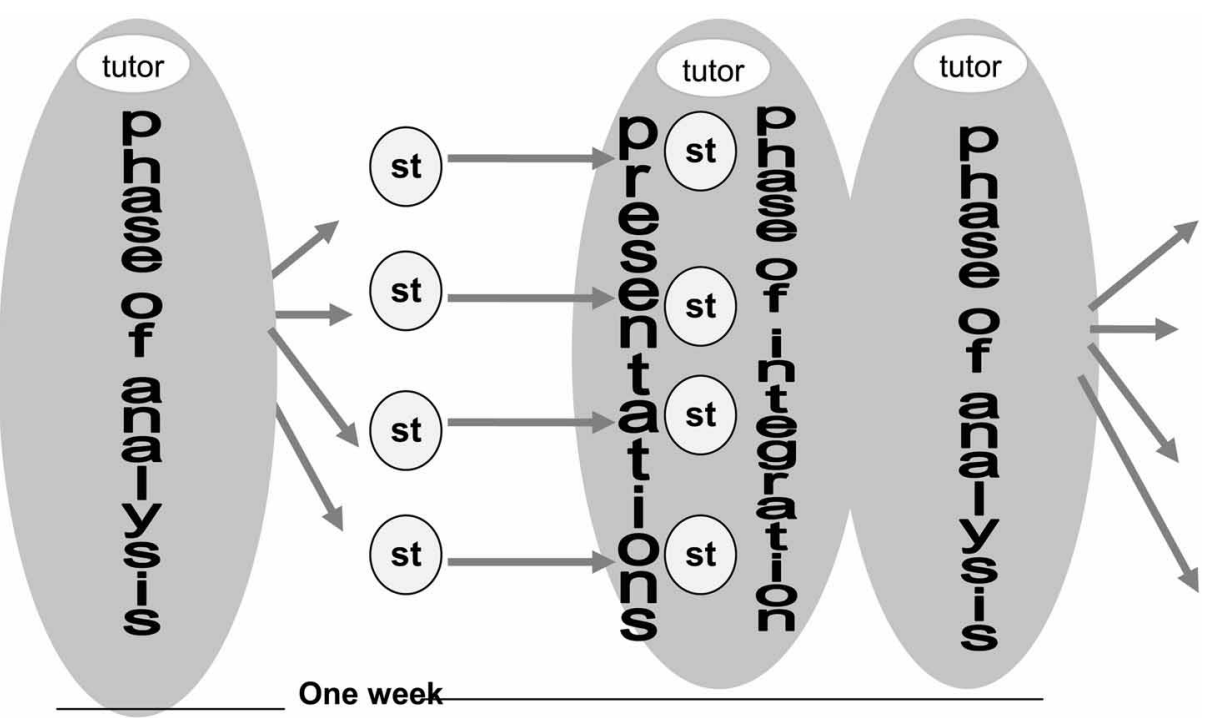

Figure 1. Schematic overview of a PBL with study teams' learning environment. 
(block B) was part of the Human Movement Science stream and focused on physical, biological and neurological aspects of muscles and coordinated movement.

In these blocks, all students from the two different streams had to work according to the study team approach. The first experiment was performed in the 2000-2001 academic year. As a result of the evaluation of that experiment, the amount of guidance was reduced for the second experiment, which was carried out in 2001-2002 (Vermunt \& Dahlmans, 2003). In 2000-2001, students were bound to relatively fixed role descriptions (e.g. the role of chairman, presenter and discussant) and procedures concerning a portfolio. In 2001-2002, students were given more latitude on both counts. This means that the two experiments were performed on different cohorts of students. Since the raw data of these cohorts were lost, we are not able to report statistical significance.

In order to answer the first research question, a closed-ended questionnaire was administered to the students at the end of the block together with the regular block evaluation questionnaire. The closed questions invited responses to statements on a 5-point Likert-scale ( $1=$ totally disagree, $5=$ totally agree) or asked students to rate some parts of the programme on a 10-point scale $(1=$ very poor, $10=$ excellent $)$. In order to answer the second research question, we asked students at the end of the block how much time they had spent studying, apart from contact time with teachers, such as tutorial group sessions, practicals and lectures.

For the third research question, we compared the results of the end-of-block test of one of the experimental blocks with the results on the test at the end of the corresponding traditional PBL block in the two preceding academic years.

\section{Results}

A $100 \%$ response rate was achieved as the questionnaires were part of the regular evaluation at the end of the last meeting of the tutorial group in that block.

\section{Do students appreciate PBL with study teams?}

The results regarding students' appreciation of working in a PBL environment with study teams are provided in Table 2. At the end of the second experiment, the students' appreciation was higher than at the end of the first experiment. The rather large standard deviations suggest that there were considerable differences between the students. In block A, the effects were stronger and more stable than in block B.

In 2001-2002 the scores improved as a result of changes, as previously mentioned, in the procedure used in the study teams. The higher level of appreciation in the second experimental year seems to be due to the higher level of freedom given to students in the study teams. 
Table 2. Students' appreciation of PBL with study teams in two blocks in the academic years 2000-2001 and 2001-2002 (means and standard deviations of responses to the questionnaire)

\begin{tabular}{llllll}
\hline & \multicolumn{2}{c}{ Block A } & & \multicolumn{2}{c}{ Block B } \\
\cline { 2 - 3 } \cline { 5 - 6 } & $\begin{array}{c}2000-2001 \\
N=42\end{array}$ & $\begin{array}{c}2001-2002 \\
N=47\end{array}$ & & $\begin{array}{c}2000-2001 \\
N=45\end{array}$ & $\begin{array}{c}2002-2002 \\
N=72\end{array}$ \\
\hline Question & $2.5(1.1)$ & $3.6(1.1)$ & & $2.7(1.2)$ & $3.0(1.2)$ \\
\hline $\begin{array}{l}\text { Is learning in a study team } \\
\text { useful?* }\end{array}$ & $3.7(0.9)$ & $4.0(1.0)$ & & $3.1(1.2)$ & $3.8(0.8)$ \\
$\begin{array}{c}\text { Was your study team } \\
\text { productive?* }\end{array}$ & $5.6(1.3)$ & $7.4(1.4)$ & & $5.7(1.5)$ & $6.3(1.7)$ \\
$\begin{array}{c}\text { Give a grade for working in a } \\
\text { study team** }\end{array}$ & $5.6(1.5)$ & $6.7(1.3)$ & & $6.0(1.2)$ & $5.8(1.4)$ \\
$\begin{array}{c}\text { Give a grade for the PBL with } \\
\text { study teams format** }\end{array}$ & 5.6 & & & \\
\hline
\end{tabular}

*Response on five-point Likert scale. **Response on 10-point scale.

How much time do students spend studying?

Table 3 shows the study time reported by the students for the traditional PBL format and the PBL with study teams' format of the two blocks. In the PBL with study teams' format, students reported more study time than in the traditional PBL format. In both experimental blocks, the amount of study time doubled. A large part of the extra study time was spent working in the study team.

\section{Do students' achievements improve?}

In addition to the question about study time, it is also interesting to explore whether there was any qualitative improvement. Although a separate study will address that research question, there are already some preliminary results of higher grades at the end of the study group blocks (see Table 4).

\section{Discussion and conclusions}

The purpose of the experiment with PBL with study teams was to investigate whether students appreciated the study team format and whether they studied more intensively in terms of time and did better on a test. The results suggest that study teams enhance self-directed learning and counteract the detrimental effects of too simple problems, too much guidance and too large groups on students' active engagement. The outcomes of the first research question (Table 2) after the first experiment suggest that the students were not overly enthusiastic about the study team format. However, after changing the format on the basis of the evaluation of the first experiment, the results of the second 
Table 3. Study time reported by the students in a traditional PBL format and in a PBL with study teams' format in numbers of hours

\begin{tabular}{|c|c|c|c|c|c|c|}
\hline \multirow[b]{3}{*}{ Activity } & \multicolumn{3}{|c|}{ Block A } & \multicolumn{3}{|c|}{ Block B } \\
\hline & \multirow[b]{2}{*}{$\begin{array}{c}\text { Traditional PBL } \\
1999-2000 \\
N=48\end{array}$} & \multicolumn{2}{|c|}{ PBL with study teams } & \multirow[b]{2}{*}{$\begin{array}{c}\text { Traditional PBL } \\
\begin{array}{c}1999-2000 \\
N=81\end{array}\end{array}$} & \multicolumn{2}{|c|}{ PBL with study teams } \\
\hline & & $\begin{array}{c}2000-2001 \\
N=42\end{array}$ & $\begin{array}{c}2001-2002 \\
N=47\end{array}$ & & $\begin{array}{c}2000-2001 \\
N=45\end{array}$ & $\begin{array}{c}2001-2002 \\
N=72\end{array}$ \\
\hline Time with Tutorial group* & 4 & 2 & 2 & 4 & 2 & 2 \\
\hline Self study** & $13.8(5.8)$ & $10.9(6.5)$ & $11.6(5.2)$ & $11.8(5.4)$ & $13.8(9.0)$ & $18.8(8.8)$ \\
\hline Study team** & - & $12.1(4.9)$ & $14.9(4.9)$ & - & $13.6(6.6)$ & $08.2(5.2)$ \\
\hline
\end{tabular}

*Scheduled number of hours per week. **Reported mean number of hours per week and standard deviation. 
Table 4. Results of the end-of-block tests of blocks with identical content in traditional PBL format and the PBL with study teams/ format (Block B). Scores by subject matter and the overall mark

\begin{tabular}{|c|c|c|c|c|c|c|c|c|}
\hline \multirow[b]{3}{*}{ Subject matter } & \multicolumn{4}{|c|}{ Traditional PBL } & \multicolumn{4}{|c|}{ PBL with study teams } \\
\hline & \multicolumn{2}{|c|}{$\begin{array}{c}1998-1999 \\
N=71\end{array}$} & \multicolumn{2}{|c|}{$\begin{array}{c}1999-2000 \\
N=81\end{array}$} & \multicolumn{2}{|c|}{$\begin{array}{c}2000-2001 \\
N=45\end{array}$} & \multicolumn{2}{|c|}{$\begin{array}{c}2001-2002 \\
N=72\end{array}$} \\
\hline & $\bar{x}$ & SD & $\bar{x}$ & $\mathrm{SD}$ & $\bar{x}$ & $\mathrm{SD}$ & $\bar{x}$ & SD \\
\hline Ground reaction force & 4.7 & $(2.2)$ & 3.6 & $(1.8)$ & 5.3 & (3.9) & 5.5 & $(2.6)$ \\
\hline Biarticular muscles & 5.1 & $(3.2)$ & 4.8 & $(2.1)$ & 6.2 & (2.9) & 7.5 & (1.9) \\
\hline Electromechanical delay & 7.2 & $(2.9)$ & 7.2 & $(2.0)$ & - & & 7.9 & (2.6) \\
\hline Rotatory biomechanics & 2.0 & $(2.4)$ & - & & 3.7 & $(2.6)$ & 3.9 & (2.9) \\
\hline Final mark & 5.2 & $(1.7)$ & 5.3 & $(1.7)$ & 6.2 & (1.1) & 6.5 & (1.1) \\
\hline
\end{tabular}


experiment showed an increase in appreciation. In 2000-2001, students were bound to relatively fixed role descriptions (chairman, presenter), as well as procedures concerning the portfolio. In 2001-2002, students were given more freedom with respect to the roles and the portfolio. In both experiments, however, the standard deviations are high, reflecting substantial variation in appreciation among the students. Several explanations may account for this variation. First, students may differ in the degree of insecurity generated by the study group format. Learning in a traditional PBL format follows a structured pattern, with students receiving feedback from their tutor on a regular basis. In the study team format students are expected to show more self-directedness. Some students find this level of insecurity easier to cope with than other students. Secondly, the experiment confronted students with several innovations simultaneously, such as analyzing more intricate problems, studying more extensive literature, presenting in a more formal way results to the other students and writing a unit portfolio. Again, students differ in their ability to cope with changes. Thirdly, in the study team format, students spent many more hours studying than in the traditional PBL format, because they had to plan extra meetings of the study teams, prepare a presentation and develop a portfolio. All these additional activities may have disturbed the working rhythm the students had developed during more than a year of conventional PBL. The new approach meant that students had to give up, change or reduce other activities outside their studies, such as employment and social activities. For some students, it was probably very difficult to change their established study habits. Underpinnings for this explanation are found in the evaluation results, where many students reported the following experience: "I learned a lot in this block, but the workload was too heavy compared with the other (traditional) blocks!'

The results on the second research question indicate that in the study team students devoted more time to their studies than in the traditional PBL format. Of course one can notice that students only give indications of their amount of study time at the end of the block and that their estimations can be distorted. We, however, do not think that this is the case. Students are familiar with questions about their amount of study time, due to the fact that this question is part of the programme evaluation questionnaire at the end of every block as part of Faculty's quality assurance activities. Moust (1993) and Van Berkel and Van den Hurk (2001) reported relatively strong correlations between the journal approach and the end of unit approach. In the journal approach, students recorded their study efforts on a daily basis in a similar educational context. These researchers found results that are in line with the data from the programme evaluation. The students in the PBL with study teams' format reported approximately twice the number of hours for study activities compared with students in the traditional PBL format. These outcomes are not really surprising. The discussions in the study team and the presentation in the tutorial group meeting necessitate a good deal of time consuming 
preparation. Unexpected, however, was the fact that the total amount of study time almost doubled despite halving contact time. The increased amount of time for self-study offers no evidence that PBL with study teams actually results in subject matter being processed at a deeper level. Here prudence is in order as our data are restricted. The test results and tutors' comments in meetings with tutors during the blocks indicate that students acquire more meaningful knowledge. The various opportunities that PBL with study teams offer for individual and collaborative elaboration activities may be interpreted as support for the conclusion that students study at a deeper level of understanding. Students have more opportunities to discuss differences of opinion, fill in gaps in their knowledge and build up a shared knowledge base. Students have more opportunities to verbalize their thoughts, consider the meaning of concepts, reason and provide arguments to support their opinions while solving or clarifying the problem. Moreover, because the study team is small and offers a context in which help is easily available, students may be less embarrassed to show their vulnerability when they have difficulty mastering a topic. The results, however, do not justify any firm conclusions as to whether or not PBL with study teams fosters deeper understanding of subject matter compared with a traditional PBL environment. We recommend further research on this subject. Such a study might involve comparison of concept maps for course topics developed by students working in a traditional PBL format with those developed by students working in a PBL with study teams' environment.

\section{References}

De Grave, W.S. (1998). Probleemgestuurd leren als kennisconstructie [Problem-based learning as knowledge construction]. Unpublished doctoral dissertation, Maastricht University. Maastricht: Maastricht University Press.

Dolmans, D.H., Wolfhagen, H.A., Van Der Vleuten, C.P. \& Wijnen, W.H. (2001). Solving problems with group work in problem-based learning: hold on to the philosophy. Medical Education, 35, 884-889.

Houlden, R.L., Collier, C.P., Frid, P.J., John, S.L. \& Pross, H. (2001). Problems identified by tutors in a hybrid problem-based learning curriculum. Academic Medicine, 76, 81.

LOHMAn, M.C. \& Finkelstein, M. (2000). Designing groups in problem-based learning to promote problem-solving skill and self-directedness. Instructional Science, $28,291-307$.

Moust, J.H. (1993). De rol van tutoren in probleemgestuurd onderwijs. Contrasten tussen student- en docent-tutoren. [The role of tutors in problem-based learning. Contrasts between student tutors and staff tutors]. Unpublished PhD-thesis. Maastricht: Datawyse.

Moust, J.H., VAn Berkel, H. \& Schmidt , H.G. (in press). Signs of erosion: Reflections on three decades of problem-based learning in Maastricht. Higher Education, in press. 
SCHMIDT, H.G. (1993). Foundations of problem-based learning: Some explanatory notes. Medical Education, 27, 422-432.

SCHMIDT, H.G. \& MousT, J.H.C. (2000). Factors affecting small-group learning: A review of research. In: D.H. Evensen \& C.E. Hmelo (Eds), Problem-based learning. A research perspective on learning interactions. Mahwah, NJ: Lawrence Erlbaum Ass.

VAN Berkel, H. \& VAN Den Hurk, M. (2001). Studiegedrag van studenten gezondheidswetenschappen. Een onderzoek naar de tijdsbesteding van studenten. [Study behaviour of students in the Faculty of Health Sciences. An investigation of students' way of studying in a PBL curriculum]. Interne nota vakgroep Onderwijsontwikkeling en - research, Universiteit Maastricht. [Internal Report of the Departement of Educational Development and Research, Maastricht University].

Vermunt, J. \& DAhlmans, H. (2003). Improving problem based student learning through selfdirecting study teams. Paper paper presented at the 10th Biennial Earli Conference, Padova. Abstracts of the 10th Biennial Earli Conference. Padova, CLEUP. 